\title{
Development of Emulsified Concentrate (EC) formulation of Mentha piperita oil for control of mosquito larvae
}

\author{
Peevush Kumar ${ }^{*}$, Sapna Mishra, Anushree Malik, Santosh Satya \\ From Challenges in malaria research \\ Basel, Switzerland. 10-12 October 2012
}

\section{Background}

Malaria is a leading cause of morbidity and mortality with an estimated 2.2 billion reported cases and 0.7 million annual deaths [1]. Continued research for malaria control although has resulted in significant reduction in malaria mortality rate, investigative measures are needed to address the escalating cost and threat of pesticide resistance. In this direction, biological control agent such as essential oil presents a good alternative [2-4]. However, the commercial applicability of essential oils for mosquitoes control is plagued by their slow action, variable efficacy and lack of suitable/user friendly end product [5]. Thus, in the present study Emulsified concentrate (EC) formulation of Mentha piperita oil, an effective mosquito larvicide $[2,3]$, was prepared and characterized.

\section{Methods}

Emulsified concentrate (EC) formulation of M. piperita oil was prepared by mixing (w/w) $40 \%$ oil, $45 \%$ aeromax, $3 \%$ butanol-1 and $12 \%$ surfactants (CABS-70 and NP-20), which was homogenized at $5000 \mathrm{rpm}$ for $30 \mathrm{~min}$. prepared EC formulation was characterized for its creaming kinetics, droplet size distribution, zeta potential, viscosity, $\mathrm{pH}$, conductivity and flash point. Formulation was also assessed for the effect of different temperature $(4,15,30$, 45 and $60^{\circ} \mathrm{C}$ ) under storage condition.

\section{Results}

EC formulation was reddish in appearance with a creaming volume of $0.4 \%$ and particle size of $563.7 \mathrm{~nm}$. Zeta potential of the resultant emulsion was $-45.9 \mathrm{mV}$. The EC formulation showed a viscosity of $25 \mathrm{cP}$ while its $\mathrm{pH}$ was slightly acidic at 6.6. The value of conductivity and flash point for $\mathrm{EC}$ was $8.8 \mathrm{mS} / \mathrm{cm}$ and $92^{\circ} \mathrm{C}$, respectively. $\mathrm{EC}$ formulation was stable at the temperature of $4,15,30^{\circ} \mathrm{C}$ and to some extent even at $45^{\circ} \mathrm{C}$. The temperature of $60^{\circ} \mathrm{C}$ was not suitable for EC stability and resultant emulsion showed phase separation.

\section{Conclusions}

Low creaming volume and negative value of Zeta potential indicated a stable emulsion. Relatively high flash point of the product observed in this study, makes it less volatile and safer to transport and handle. Temperature stability for storage signifies formulation utility in different conditions of thermal variation. The prepared formulation being applicable as emulsion could be suitably used for control of mosquitos' larvae in various aquatic habitats.

Published: 15 October 2012

\section{References}

1. World Health Organization: 2011 [http://www.who.int/research].

2. Ansari MA, Vasudevan P, Tandon M, Razdan RK: Larvicidal and mosquito repellent action of peppermint (Mentha piperita) oil. Bioresour Technol 2000, 71:267-271.

3. Ansari MA, Mittal PK, Razdan RK, Sreehari U: Larvicidal and mosquito repellent activities of Pine (Pinus longifolia, Family: Pinaceae) oil. J Vect Borne Dis 2005, 42:95-99.

4. Amer A, Mehlhorn H: Larvicidal effects of various essential oils against Aedes, Anopheles, and Culex larvae (Diptera, Culicidae). Parasitol Res 2006, 99:466-472.

5. Kumar P, Mishra S, Malik A, Satya S: Insecticidal properties of Mentha species: a review. Ind Crops Prod 2011, 34:802-817.

doi:10.1186/1475-2875-11-S1-P58

Cite this article as: Kumar et al:: Development of Emulsified Concentrate (EC) formulation of Mentha piperita oil for control of mosquito larvae. Malaria Journal 2012 11(Suppl 1):P58.

Applied Microbiology laboratory, Centre for Rural Development \&

Technology Indian Institute of Technology Delhi, New Delhi-110016, India

(C) 2012 Kumar et al; licensee BioMed Central Ltd. This is an Open Access article distributed under the terms of the Creative Commons Attribution License (http://creativecommons.org/licenses/by/2.0), which permits unrestricted use, distribution, and reproduction in any medium, provided the original work is properly cited. 